\title{
Pelatihan Manajemen Pemeliharaan Ayam Jantan Petelur pada Kelompok Ternak Nawawi Farm Jember
}

\author{
M. Adhyatma ${ }^{1 *}$, Gayuh Syaikhullah ${ }^{2}$, Rizki Amalia Nurfitriani ${ }^{3}$, Nur Muhamad ${ }^{4}$, Satria Budi Kusuma ${ }^{5}$ \\ 1,3,4,5Program Studi Produksi Ternak, Jurusan Peternakan, Politeknik Negeri Jember, Jember. \\ ${ }^{2}$ Program Studi Manajemen Bisnis Unggas, Jurusan Peternakan, Politeknik Negeri Jember, Jember. \\ Im_adhyatma@polije.ac.id
}

\begin{abstract}
"Nawawi Farm" Breeder Group of Nogosari Village is one of the breeder's groups community in Jember Regency which has a focus on layer rooster's commodity business. Members of this group are approximately 100 breeders. Production of laying hens has a final weight of around $800 \mathrm{~g}$. Meanwhile, feeding during maintenance requires quite a lot of cost. The existence of expenditures made and income generated is unbalanced, of course, become quite serious problems in the world of the livestock business. This is due to the lack of understanding of the Nawawi Farm livestock group regarding the maintenance management of Laying Roosters. Therefore, training and educations are needed regarding the maintenance management of laying hens. The service of the community dedication stage begins with analyzing community needs, training in the management of laying hens, to guiding the maintenance of laying hens in the Nawawi Farm Livestock Group. The main results of the implementation of this service carried out is that all Nawawi Farm breeders can understand the maintenance management of Laying Hens properly and correctly. The service activities that have been carried out can be carried out properly and run smoothly in accordance with the planned activities that have been prepared. This community service activity was well-received by all apparatus of the Nawawi Farm breeder group. The suggestion of this activity is a follow-up activity in the form of training on making rations with the use of local feed ingredients, especially in the face of the new normal era now to maintain the economic stability of the Nawawi Farm livestock group.
\end{abstract}

Keywords: layer rooster's, livestock, local feed.

\begin{abstract}
Abstrak
Kelompok Peternak "Nawawi Farm" Desa Nogosari merupakan salah satu Kelompok Peternak di Kabupaten Jember yang memiliki fokus komoditas usaha di Ternak Ayam Jantan Petelur. Jumlah kelompok ternak terdiri dari kurang lebih 100 peternak. Produksi ayam jantan petelur memiliki bobot akhir sekitar 800 g. Sementara itu, pemberian pakan selama pemeliharaan membutuhkan biaya yang cukup banyak. Adanya pengeluaran yang dilakukan dan pendapatan yang dihasilkan tidak seimbang, tentunya menjadi permasalahan cukup serius dalam dunia usaha peternakan. Hal ini diakibatkan karena belum pahamnya kelompok ternak Nawawi Farm mengenai manajemen pemeliharaan Ayam Jantan Petelur (AJP). Oleh karena itu, perlu dilakukan pelatihan mengenai manajemen pemeliharaan ayam jantan petelur. tahapan pengabdian diawali analisis kebutuhan masyarakat, pelatihan manajemen pemeliharaan ayam jantan petelur, hingga pembimbingan pemeliharaan ayam jantan petelur di Kelompok Ternak Nawawi Farm. Hasil utama dari pelaksanaan pengabdian yang dilakukan yaitu seluruh kelompok peternak Nawawi Farm dapat memahami manajemen pemeliharaan dari Ayam Jantan Petelur dengan baik dan benar. Pelaksanaan kegiatan pengabdian yang telah dilakukan dapat terselenggara dengan baik dan berjalan lancar sesuai dengan rencana kegiatan yang telah disusun. Kegiatan pengabdian ini mendapat sambutan baik dari perangkat seluruh kelompok peternak Nawawi Farm. Saran dari kegiatan ini yaitu kegiatan lanjutan berupa pelatihan pembuatan ransum dengan pemanfaatan bahan pakan lokal khususnya dalam menghadapi era new normal sekarang ini untuk menjaga stabilitas perekonomian kelompok ternak Nawawi Farm, Kabupaten Jember.
\end{abstract}

Kata Kunci: Ayam Jantan Petelur, Peternakan, Pakan Lokal

*Penulis Korespondensi : M. Adhyatma 


\section{PENDAHULUAN}

Kelompok Peternak "Nawawi Farm" Desa Nogosari merupakan salah satu Kelompok Peternak di Kabupaten Jember yang memiliki fokus komoditas usaha di Ternak Ayam Jantan Petelur. Jumlah kelompok ternak terdiri dari kurang lebih 100 peternak. Produksi ayam jantan petelur memiliki bobot akhir sekitar $800 \mathrm{~g}$. Sementara itu, pemberian pakan selama pemeliharaan membutuhkan biaya yang cukup banyak. Adanya pengeluaran yang dilakukan dan pendapatan yang dihasilkan tidak seimbang, tentunya menjadi permasalahan cukup serius dalam dunia usaha peternakan.

Permasalahan yang umum terjadi pada usaha peternakan sesuai permasalahan yang ada pada Kelompok Peternak "Nawawi Farm" diantaranya penanganan DOC, pemberian vaksin, pemberian pakan, serta saat budidaya. Hal itu termasuk dalam manajemen pemeliharaan. Manajemen merupakan faktor penting dalam menentukkan berhasil atau tidaknya suatu usaha khususnya usaha peternakan, sehingga penting untuk dipelajari dengan baik.

Adanya permasalahan yang ada di Kelompok Peternak "Nawawi Farm" menjadi perhatian penuh yang harus dicarikan solusinya. Salah satu solusi yang dapat dilakukan adalah melakukan pelatihan serta pembimbingan kepada Kelompok Peternak "Nawawi Farm" Desa Nogosari tentang manajemen pemeliharaan ternak.

Ayam jantan petelur merupakan ayam kelompok ras petelur yang tidak memiliki nilai jual besar. Hal ini menjadi peluang untuk dimanfaatkannya ayam jantan petelur sebagai penghasil daging, seperti yang sudah dilakukan oleh Kelompok Peternak "Nawawi Farm" Desa Nogosari. Ayam Jantan Petelur memiliki kemampuan budidaya yang lebih cepat dibandingkan ayam betina jika sistem pemeliharaan diterapkan dengan baik.

Berdasarkan analisis situasi pada Mitra Usaha dapat diketahui beberapa permasalahan yang sekiranya perlu segera dicari solusi alternatifnya adalah permasalahan peningkatan keterampilan Kelompok Peternak "Nawawi Farm" Desa Nogosari dalam manajemen pemeliharaan ternak Ayam Jantan Petelur agar memiliki kemampuan yang baik. Sehingga peningkatan keterampilan sekiranya dapat lebih menambah wawasan mengenai manajemen pemeliharaan ternak yang baik dan ekonomis.

\section{METODE}

Adapun tahapan pelaksanaan kegiatan Pelatihan Manajemen Pemeliharaan Ayam Jantan Petelur Untuk
Peningkatan Keterampilan Kelompok Peternak "Nawawi Farm" Desa Nogosari adalah sebagai berikut:

\subsection{Analisis kebutuhan masyarakat}

Melakukan survei awal pada kelompok ternak serta mencari informasi mengenai hal yang dibutuhkan oleh mitra yang dijadikan sebagai dasar melakukan pelatihan. Permasalahan yang dihadapi oleh Kelompok Peternak "Nawawi Farm" adalah kurang pahamnya peternak mengenai manajemen pemeliharaan Ayam Jantan Petelur sebagai penghasil daging. Hal ini tentunya menjadi hal penting yang perlu diperhatikan mengingat harus berkembangnya usaha peternakan Ayam Jantan Petelur di wilayah Jember Selatan.

\subsection{Pelatihan Manajemen Pemeliharaan Ayam Jantan Petelur}

Pelatihan dilakukan dengan tahapan pemberian materi terlebih dahulu. Pemberian materi disajikan dalam bentuk Power Point. Adapun materi yang akan disampaikan diantaranya mengenai persiapan yang perlu dilakukan sebelum DOC datang, pemeliharaan DOC yang baik, manajemen pemberian pakan, dan sistem rekording. Pemberian materi akan dilakukan kurang lebih satu hari penuh dengan jeda waktu istirahan pukul 11.00 WIB sampai 13.00 WIB dan selesai pukul 15.00 WIB. Adanya pemberian materi terlebih dahulu diharapkan peternak memahami mengenai pentingnya dilakukan manajemen pemeliharaan ayam jantan petelur dengan baik, sehingga dapat dipraktikan dalam lapangan dengan baik pula.

\subsection{Pembimbingan Pemeliharaan Ayam Jantan Petelur}

Pembimbingan kepada peternak dilakukan setelah pemberian materi. Bentuk pembimbingan yang diberikan adalah dengan dilakukan praktik pemeliharaan yang disesuaikan dengan jadwal masukanya ternak (DOC). Peternak akan dibimbing dimulai dari persiapan sebelum DOC datang sampai pemanenan.

\section{HASIL DAN PEMBAHASAN}

Pengabdian kepada masyarakat dilaksanakan dengan melakukan pelatihan kepada Kelompok Ternak Desa Nogosari mengenai Manajemen Pemeliharaan Ayam Jantan Petelur. Adapan sebelum melakukan pelatihan, diadakan terlebih dahulu analisis kebutuhan masyarakat peternak dalam bentuk Focus Group Discussion (FGD) di Desa Nogosari, Kecamatan Rambipuji, Kabupaten Jember. Hasil dari FGD tersebut diinterpretasikan dalam bentuk pelatihan dengan judul "Pelatihan Manajemen Pemeliharaan Ayam Jantan Petelur untuk Peningkatan Keterampilan Kelompok Ternak Desa Nogosari". Adanya pelatihan ini menjadi solusi dalam 
penyelesaian masalah Kelompok Peternak Desa Nogosari sehingga Peternak menjadi terampil dalam melakukan manajemen pemeliharaan ternak Ayam Jantan Petelur.

\subsection{Analisis Kebutuhan Masyarakat}

Analisis kebutuhan masyarakat adalah tahapan pertama dalam pelaksanaan Pengabdian kepada Masyarakat ini. Tahap ini dilakukan dengan membuat Focus Group Discussion (FGD) dengan mitra yaitu Kelompok Peternak Desa Nogosari. Hasil FGD ini terdiri dari beberapa permasalahan yang terjadi di Kelompok Peternak tersebut, yaitu belum pahamnya peternak dalam melakukan sanitasi kandang, penanganan DOC, pemeliharaan, perhitungan FCR, hingga perhitungan keuntungan usaha dalam pemeliharaan Ayam Jantan Petelur tersebut.

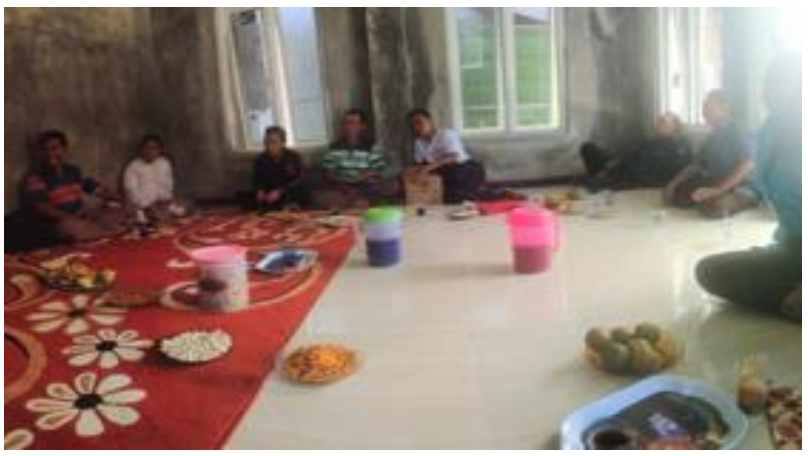

Gambar 1. FGD bersama Kelompok Ternak Nawawi Farm.

\subsection{Pelatihan Manajemen Pemeliharaan Ayam Jantan Petelur}

Pelaksanaan pelatihan dilaksanakan di Rumah Makan Kembang, Kecamatan Ajung, Kabupaten Jember. Adapun materi yang diberikan saat pelatihan tersebut diantaranya sebagai berikut:

\section{Manajemen Ayam Jantan Petelur}

Materi yang diberikan ini dimulai dari penjelasan mengenai persiapan kandang. Persiapan kandang yang harus diperhatikan yaitu bentuk pemeliharaan lebih baik menggunakan sistem all in all out. Hail ini bertujuan untuk menyeragamkan usia ternak agar lebih mudah untuk ditangani. Selain itu, masa pembersihan kandang disarankan dilakukan minimal 14 hari sebelum DOC masuk. Penanganan pembersihan ini penting dilakukan untuk mencegah terjadinya kontaminasi dari mikroorganisme merugikan yang akan berpengaruh pada masa pemeliharaan ternak. Kemudian, peternak diberikan penjelasna mengenai Pencucian kandang dilakukan secepat mungkin menggunakan detergen dan air bersih, kemudian disemprot menggunakan formalin $10 \%$. Lantai kandang diberi kapur dengan komposisi $10 \mathrm{~kg}$ kapur hidup, $20 \mathrm{~kg}$ ammonium sulfat untuk lantai dengan luas $100 \mathrm{~m}^{2}$. Selain itu, peternak juga diberikan wawasan mengenai tahapan brooding, tujuan brooding untuk menyediakan lingkungan yang nyaman dan sehat secara efisien dan ekonomis bagi anak ayam untuk pertumbuhan optimal. Tahapan brooding diantaranya manajemen pemeliharaan DOC dimana sebelum DOC tiba, harus tersedia pakan dan air minum dalam kandang (Rasyaf, 2012).

Peternak juga diberikan pengetahuan mengenai kepadatan ayam dan pemasangan tirai. Kepadatan ayam penting diperhatikan mengingat kenyamanan ayam yang harus terjaga agar produktivitas yang dihasilkan sesuai dengan target pencapaian. Jumlah ayam setiap meter persegi dapat bervariasi tergantung usia panen. Kandang dengan sistem open house menggunakan ventilasi alami memiliki kepadatan maksimal 15 $\mathrm{kg} / \mathrm{m}^{2}$. Jenis kendang dengan aliran udara yang bias diatur atau disebut dengan kendang closed house memiliki kepadatan 25 $30 \mathrm{~kg} / \mathrm{m}^{2}$ berat hidup. Pemasangan tirai dilakukan sesuai dengan kebutuhan dan kondisi lingkungan. Cara membuka tirai dilakukan dari atas ke bawah untuk mencegah agar ayam tidak terkena angin secara langsung. Tirai samping pada bagian atas terbuka $\pm 0,2-0,3 \mathrm{~m}$. Apabila udara dingin maka dianjurkan untuk ditambahkan tirai kembali pada kendang bagian dalam. Apabila anak ayam mulai panting di usia 2-3 hari maka tirai dibuka pada bagian tengah (Fadilah dan Fatkhuroji, 2013).

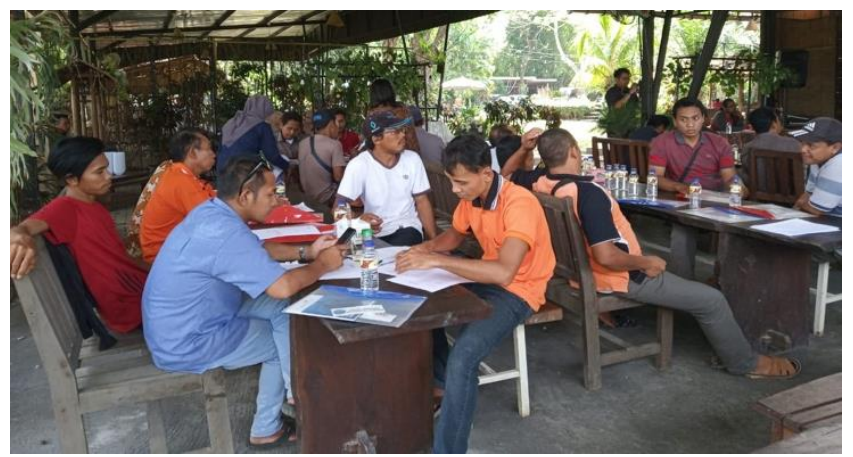

Gambar 2. Pemberian Materi kepada Kelompok Ternak Nawawi Farm.

Sistem pemberian pakan yang dijelaskan kepada peternak yaitu terdiri dari beberapa komponen yaitu tempat pakan (Feeder Space) untuk anak ayam. Tempat pakan ayam mulai hari ke-3 harus sudah ditambahkan pan feeder, pada hari ke-6 feeder tray sudah mulai dikeluarkan dan hari ke-9 sudah menggunakan feeder tube. Hari ke-12 feeder tube sudah mulai digantung. Selain tempat pakan, tempat minum juga menjadi komponen penting dalam sistem pemberian pakan. Air minum harus tersedia setiap saat, serta diberikan antibiotic pada hari 
ke-1 hingga hari ke-3 saat pagi hari dan vitamin saat sore hari. Ketinggian nipple disesuaikan secara sentral menggunakan alat sehingga ayam dapat minum dengan mengangkat kepala menuju tempat minum sebesar $45^{\circ}$ (Tamalludin, 2012).

Pelaksanaan panen untuk ayam jantan petelur sama seperti pada pemanenan broiler umumnya dimana untuk melihat berhasil atau tidaknya pemeliharaan ternak dilihat dari performa ternak. Performa ternak ayam jantan petelur dihitung menggunakan European Production Efficiency Factor (EPEF) atau disebut dengan Faktor Efisiensi Produksi. EPEF merupakan standar perhitungan performan teknis meliputi berat hidup, konversi pakan, umur dan kematian normal yang diukur di rumah potong (Fadilah dan Fatkhuroji, 2013).

\subsection{Pembimbingan Kelompok Ternak Nawawi Farm}

Pembimbingan dilakukan setelah pemberian materi mengenai manajeman pemeliharaan ayam jantan petelur. Hasil pembimbingan didapatkan bahwa peternak lebih memahami cara manajemen pemeliharaan ayam jantan petelur setelah diberikan pemahaman mengenai materi pemeliharaan tersebut. Hal ini terlihat dari sistem perkandangan yang lebih tertata dibadingkan sebelumnya. Selain itu, dalam persiapan masuknya ayam ke kandang juga kebih higienis dibandingkan sebelumnya terlihat bahwa dilakukan penyemprotan disinfektan terlebih dahulu sebelum ternak dimasukkan ke dalam kandang, serta dilakukan pembersihan dan penyebaran kapur untuk menjaga agar tidak tumbuh mikroba patogen yang dapat menghambat pertumbuhan ternak.

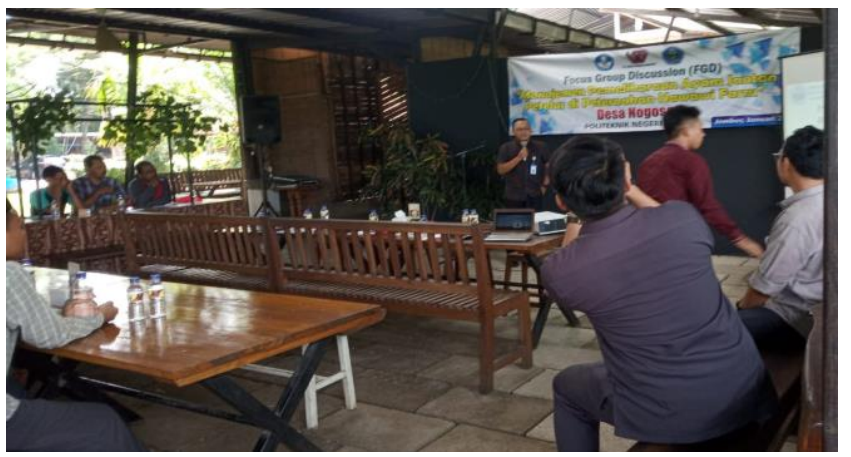

Gambar 3. Pembimbingan kepada Kelompok Ternak Nawawi Farm.

Selama pemeliharaan berlangsung, tim melakukan monitoring selama setiap 2 minggu sekali yaitu dengan melihat bagaimana sistem manajemen pemeliharaan ayam jantan petelur, mulai dari rekording hingga pembuangan limbah ternak tersebut. Manajemen pemeliharaan yang diterapkan oleh peternak menunjukkan hasil yang lebih baik dibandingkan dengan sebelum pemberian materi. Hal ini terlihat dalam proses pemeliharaan peternak yang lebih teratur dimana pakan terlebih dahulu ditimbang untuk setiap harinya.

Penimbangan dilakukan agar pemberian pakan tidak berlebih dan tidak kurang. Selain itu, penimbangan pakan juga dilakukan untuk mengukur pakan yang dikonsumsi ternak apakah ada yang tersisa atau tidak sebagai indikator dalam menghitung efisiensi pakan dan feed conversion ratio (FCR). Hasil FCR menunjukkan angka yang bagus, dimana setelah pemberian pakan yang dilakukan dengan baik dan sistematis, maka evaluasi pakan dapat dilakukan. Adanya FCR yang baik maka peternak akan dengan mudah menghitung keuntungan atau memperkirakan keuntungan yang diperoleh, sehingga kedepannya peternak dapat melakukan rancangan usaha peternakan dengen lebih tertatat mulai dari persiapan kandang, persiapan pakan, persiapan masuknya ternak, pemeliharaan, hingga pemasaran hasil produksi tersebut.

\section{KESIMPULAN}

Kegiatan pengabdian ini telah dilaksanakan selama 6 bulan dengan tahapan pengabdian diawali analisis kebutuhan masyarakat, pelatihan manajemen pemeliharaan ayam jantan petelur, hingga pembimbingan pemeliharaan ayam jantan petelur di Kelompok Ternak Nawawi Farm. Hasil utama dari pelaksanaan pengabdian yang dilakukan yaitu seluruh kelompok peternak Nawawi Farm dapat memahami manajemen pemeliharaan dari Ayam Jantan Petelur dengan baik dan benar. Pelaksanaan kegiatan pengabdian yang telah dilakukan dapat terselenggara dengan baik dan berjalan lancar sesuai dengan rencana kegiatan yang telah disusun.

Kegiatan pengabdian ini mendapat sambutan baik dari perangkat seluruh kelompok peternak Nawawi Farm. Saran dari kegiatan ini yaitu kegiatan lanjutan berupa pelatihan pembuatan ransum dengan pemanfaatan bahan pakan lokal khususnya dalam menghadapi era new normal sekarang ini untuk menjaga stabilitas perekonomian kelompok ternak Nawawi Farm, Kabupaten Jember.

\section{DAFTAR PUSTAKA}

[1] Rasyaf, M. 2012. Panduan Beternak Ayam Petelur. Jakarta: Penebar Swadaya. Hal: 106-109. 2.

[2] Fadilah, R. dan Fatkhuroji. 2013. Memaksimalkan Produksi Ayam Ras Petelur. Agromedia Pustaka. Jakarta.

[3] Tamalluddin, F. 2012. Ayam Broiler 22 Panen Lebih Untung. Depok: Panebar Swadaya. 6-18. 